\title{
Corporate Annual Reports in Academic Business Libraries
}

\author{
Judith R. Bernstein
}

More than twenty thousand companies distribute annual reports. These reports are collected by libraries in various media, however, an extensive literature search failed to uncover any description of these collection practices. This paper describes a survey of 500 academic business libraries that was undertaken to gather information on present practices in the acquisition, use, retention, and storage of domestic and foreign corporate annual reports as well as on policies related to their circulation and cataloging. These reports, an extremely important body of primary company information, are collected by 92 percent of those libraries responding to the survey. After describing current practices in detail, some options are proposed for libraries collecting this material.

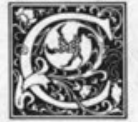

orporate annual reports are widely collected by academic business libraries as excellent descriptions of company activities. The corporate report reviews the past year's accomplishments, and provides a perspective on the future of the company. ${ }^{1}$ It is addressed to shareholders and thus is written in language that the average shareholder will understand. It is also an ideal source of information for the business student. In an expensively packaged public relations document, often costing the company thousands of dollars to produce but usually sent free to libraries, the student can get a detailed view of the company's corporate image and policies. The student can see how the company's product is displayed, identify the corporate officers, and get an indication of the type of employees the company hires. Most importantly, the annual report contains a detailed description of the company's financial balance sheet-earnings, sales, stockholders' equity, etc. Nevertheless, nothing has been written about the acqui- sition or retention of annual reports.

Despite their many benefits, annual reports pose a range of problems for the librarian. The hard-copy corporate annual report (CAR) to the shareholder must be requested from each company. The librarian must see that a request is made, the report is received, and the library stays on the mailing list for the following year. Continuous checking on responses to these requests is needed: often a company does not respond immediately and a second request must be generated. If the company is very small, phone calls may need to be made. If guidelines have been established for the library's holdings, these must be reviewed each year so that the list remains current. If selection is by individual companies in a particular industry, the list must be reviewed in order to add new companies and drop old ones.

After a few years, CARs begin to take up a great deal of space; after five or ten years, they present serious storage problems. How much historical information in this form is it necessary for the library to

Judith R. Bernstein is head of the Parish Memorial Business Library, University of New Mexico, Albuquerque, New Mexico 87131. Eileen Schroeder, formerly of the University of Mexico General Library, assisted with the statistical analysis of this report. 
keep? If space needs appreciate so rapidly, what is the best location for the CARs? Do questions of currency and security make special locations a requirement? Should they be in an area such as reference or reserve where assistance is normally available? Can older issues be located in more remote areas? Do we know how the reports are used so that we can make intelligent judgements on these issues?

Foreign corporate reports pose further problems. Many foreign companies are not generous in sending out reports and, for some, numerous requests may be to no avail. Often it is necessary to make requests in the language of the country in which the company is headquartered. Many foreign companies do not have any conception of a mailing list, and library staff must request the current reports from these companies annually. The necessity for frequently checking receipts is more critical for foreign annual reports because they may become totally unavailable if missing issues are not noted promptly and claimed immediately.

Some of the problems posed by hardcopy versions may be alleviated by collecting annual reports on microfiche supplied by commercial vendors. Microfiche may be retained for many years and use considerably less space than the original hard copies. The vendor providing the fiche is responsible for maintaining orderly receipts; however, there is a substantial cost for these fiche, and the library will still be responsible for making any changes in the company reports that are to be acquired on the subscription. In the case of foreign corporate reports, there is an added concern: it is only in the last few years that vendors have been in the business of supplying substantial numbers of reports, and we have no track record of their ability to maintain an orderly supply of them.

If the library can overcome the questions of costs, there are still a number of unanswered questions about the use of microfiche. Librarians have always felt that there is a strong reluctance on the part of the client to substitute microforms when paper is available. One consideration is that the "packaging" of the annual report is lost; for example, multicolored graphics are not cheaply produced in microform.
How important is the packaging and artistic production to one's clients as compared to those aspects that can be as easily provided in another format?

A possible alternative to the CAR is the 10-K. The Securities and Exchange Commission requires that this report be filed annually by all public companies with at least three million dollars in assets and five hundred shareholders. A few companies use the $10-\mathrm{K}$ as their annual report; others include it as an addition to their annual report, but this is not common practice. ${ }^{2}$ There are now several vendors that provide microfiche copies of $10-\mathrm{Ks}$ and related reports on a subscription or demand basis. As with annual reports on fiche, the storage of $10-\mathrm{Ks}$ is considerably less burdensome than the paper CARs, but this convenience may be offset by the substantial purchase costs as well as the need for fiche readers and printers. Questions also remain as to whether the information contained in the $10-\mathrm{K}$ is sufficiently similar to the annual report that one can be substituted for the other in library collections.

\section{THE SURVEY}

In order to answer some of the questions raised about corporate annual reports, a questionnaire was sent in March and April, 1985, to 500 libraries affiliated with institutions listed in Barron's Guide to Graduate Business $1984 .^{3}$ (Schools with fewer than twenty-five M.B.A. students were not included in the survey.) Replies were received from 340 libraries (68 percent), including 5 that did not fill out the questionnaire and 1 that filled out only one side of the two-sided form. A subset was created of those libraries that were identified as having a separate business library by the College and University Business Library Statistics 1979/80 and 1980/81 Survey. "The term 'separate' refers to those libraries that are housed in a separate building or part of a building, with a separate budget and an easily identifiable collection of materials." ${ }^{\prime 4}$ To this subset were added those libraries that were identified by Barron's in the Cartter Report as the "top schools of business." It was the author's hypothesis that the separately housed and top schools might have different practices than other academic busi- 
ness libraries. Thirty-four separately housed libraries were identified, and 7 additional schools without separate libraries were added from Barron's "top" group. In order to increase the percentage of returns, a telephone follow-up was conducted. Of the 41 libraries in this group, 90 percent (37) eventually returned the questionnaire. (See appendix A for a listing of the 37 institutions.)

The survey instrument contains twentyseven questions. Section I deals with domestic companies: questions 1-7 relate to the acquisition, storage, location, and use of the hard-copy annual reports; questions 8-13 deal with the same data as they relate to annual reports on microform; 14-17 solicit information on the acquisition and use of the $10-\mathrm{K}$ reports. Section II, questions 18-21, contains requests for information relating to foreign corporate reports. Section III contains questions on circulation, cataloging, online services, and proposed changes in annual report collection policies. Section IV solicits background information regarding the size of the library's business collection and the number of students in the graduate and undergraduate business programs. So much confusion resulted over the question of the estimated size of the collection (number of volumes versus number of titles, serials and/or monographs; inability of librarians to estimate the size of an interfiled collection) that this answer was disregarded. Only one question was intended to be open-ended, but many respondents added unsolicited and useful comments. All the responses were exam- ined and coded in the appropriate section, including those that were unsolicited.

Of the libraries responding to the survey, 75 percent (255) collect hard-copy annual reports. The number of reports collected each year range from one to twenty-five in 9 libraries to more than three thousand in 6 libraries. Of these 6,4 are in the subset of separate and top business libraries previously defined. (This group will hereafter be referred to simply as the subset.) Of the 37 libraries in the subset, 27 collect hard-copy reports; the majority collects large numbers of reports, as would be expected from major research libraries in this group. Of the total respondents, 99 libraries had just begun collections.

The responses to question 4, categories of collecting, are summarized in table 1. The collecting behavior of the subset was similar. Of the libraries collecting the Fortune 500 hard-copy reports or reports of companies headquartered in the state, the preferred locations are the reference department, special alcoves or rooms, or filing cabinets in unspecified locations. Few libraries keep these reports in the current periodical area, the regular stacks, or remote storage. The preferred locations are consistent among both the total respondents and the subset. Of the libraries retaining reports indefinitely, the majority locate them in the reference department or in special alcoves; a minority of libraries retain them on reserve for varying periods.

The largest number of libraries that specified "other" collections mentioned

TABLE 1

LIBRARIES COLLECTING HARD-COPY ANNUAL REPORTS, BY TYPE OF REPORTS AND YEARS RETAINED

\begin{tabular}{lccccc}
\hline \hline & $\begin{array}{c}\text { Total } \\
\text { Number of } \\
\text { Libraries }\end{array}$ & $1-2$ & $3-5$ & $6-10$ & Years Retained \\
Fypes Collected & 177 & 50 & 91 & 11 & 31 \\
Fortune 500 & 175 & 47 & 79 & 11 & 50 \\
Co.'s hq. in state & 54 & 9 & 24 & 4 & 19 \\
Fortune 1000 & 82 & 18 & 45 & 7 & 21 \\
Fortune 500 service & 40 & 9 & 24 & 2 & 8 \\
Forbes 500 & 71 & 20 & 26 & 3 & 21 \\
NYSE & 61 & 15 & 23 & 3 & 18 \\
AMSE & 47 & 10 & 19 & 3 & 14 \\
OTC & 59 & 17 & 24 & 4 & 15 \\
Co.'s selected by industry & & & & 4 \\
\hline
\end{tabular}

*Some respondents transfer reports from one location to another after a number of years, which accounts for the discrepancy in the totals. 
reports of locally based companies. Other categories added by respondents were those requested by faculty or students and those from companies headquartered in the region (Southwest, New England, etc.), followed by Value Line services, companies recruiting on the particular campus, and reports acquired as gifts. Many libraries indicated that they made selections from the groups rather than acquiring all companies of a particular category (i.e., all NYSE companies).

The use made of hard-copy annual reports is summarized in figure 1 . It is worth noting that those who believe the advertising or public relations aspects of the annual reports to be important are in a dis- tinct minority. Other uses for hard-copy annual reports mentioned by a few respondents are for commercial artists to note product displays; for general class assignments, accounting exercises, strategic planning, and technical writing; for noting the CEO's statement and the company's portrayal of itself; and for general investing. In the subset the responses are similar to those of the whole group.

When asked if they would throw away the hard copy if they theoretically were able to acquire microforms, 45.4 percent ( 152 libraries) said yes and 25 percent ( 83 libraries) said no. Of those who indicated the period of time they would retain hard copies before discarding, the largest num-

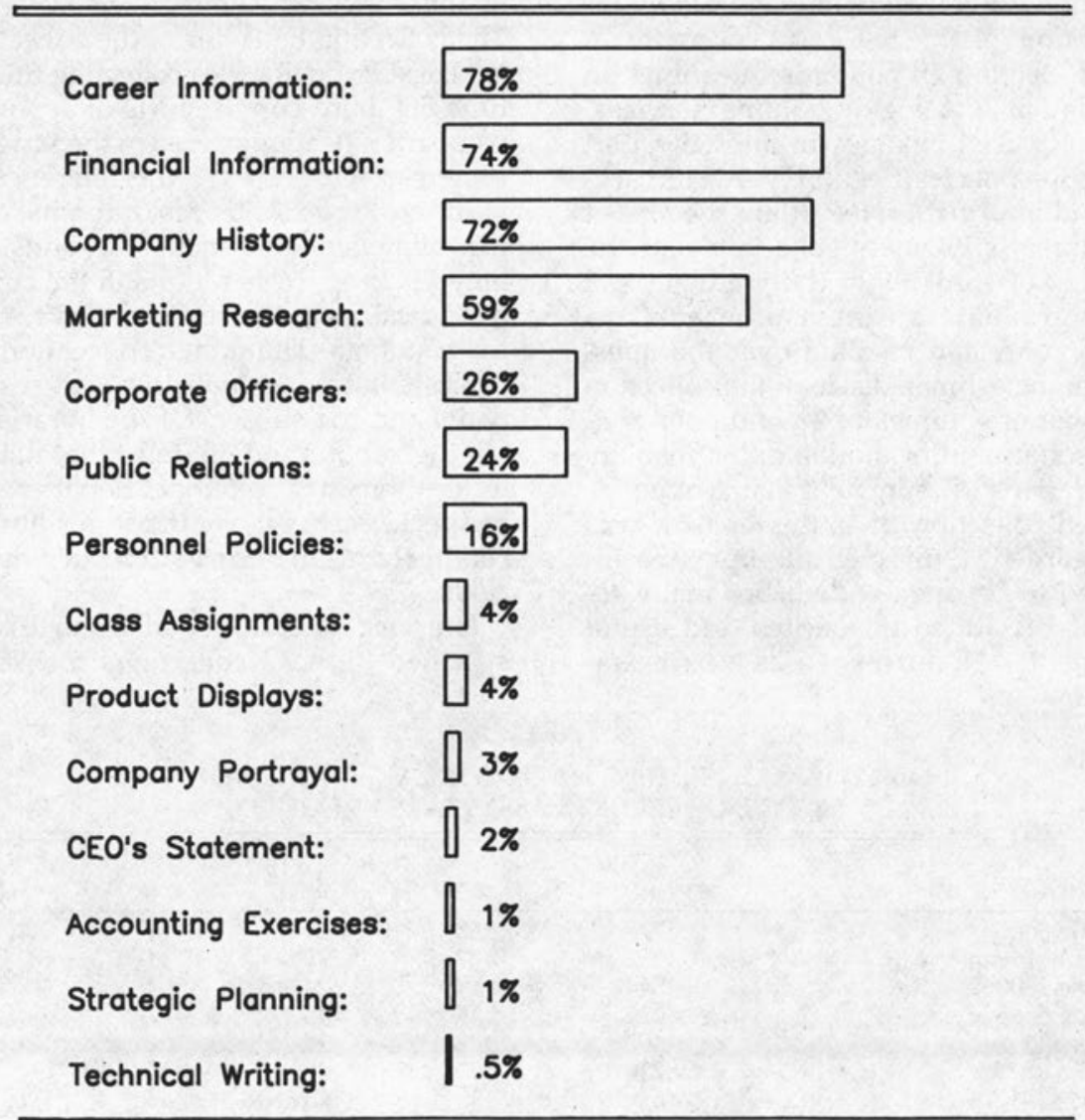

FIGURE 1

Libraries Collecting Hard-copy Annual Reports:

Percentage of Libraries Reporting Use as One of Their Top Four Choices 
ber, 25 percent, reported they would discard them after one to two years; 22 percent after three to five years, and 14 percent after six to ten years. When asked what policies they would follow in discarding, 14 libraries indicated they would discard all but their collections of local companies' annual reports-the primary reason given for discarding was lack of space. Of those libraries that indicated they would not choose to discard their hard-copy reports, reasons given were that clients objected to using microforms or wanted multicolored graphics; that microforms were too costly; and/or that there were too few reader printers. The libraries in the subset are closely divided in their decisions to discard. Of those willing to discard, the largest number expressed intent to do so after one to two years (66 percent) or three to five years (47 percent). Several large research libraries keep all material as historical information and indicated that, as large research libraries, they "never discarded anything." Otherwise, the reasons for not discarding are similar to those in the whole group.

In question 9, which solicited information about subscriptions to microform annual reports, 57 percent (191 libraries) reported that they received domestic CARs on microform. In the subset, 86 percent (32 libraries), a substantially larger percentage, collected reports on microform. One hundred nineteen libraries collecting microform reports subscribed to Q-Data for one to twelve years. Eighty-five subscribed to Disclosure Service, having done so for one to seventeen years. Of the subset, 28 libraries subscribe to Disclosure, 9 to Q-Data. Several libraries reported subscribing to the Godfrey Memorial Library's service. The percentage of subscribers to each service is somewhat misleading since some libraries reported on subscriptions that are not currently received.

Of those libraries receiving microforms, 113 reported that in some cases these duplicated their hard-copy holdings. In cases of duplication, the most frequently stated reason for retaining the hard copy was student demand (88 libraries). Only secondarily are the hard copies retained because of minimal overlap with microforms or because of the need for additional copies. The results for the subset are similar, with faculty demand given as an additional reason for retention. A very small number of each group plan to discontinue hard copies. Of the total libraries receiving microform CARs, only 39 percent replied that they currently discard the duplicates after a specified number of years.

The next group of questions concerned the acquisition and use of the SEC $10-\mathrm{K}$ reports. These reports are acquired by 89 percent of the libraries in the subset and 60 percent of the whole. In both the whole and the subset, the largest number of libraries subscribe to NYSE, the second largest to AMSE, and the least to OTC companies. Of those who indicated that they subscribe to a selected group of $10-\mathrm{K}$ reports, the predominant category of selection in the subset is local- or stateheadquartered companies. A higher percentage of libraries in the whole group select from the Fortune 500 list, with the second highest choice being local- and state-headquartered companies.

Figure 2 summarizes the results of the questions regarding use of the $10-\mathrm{Ks}$. Note the difference in perception of career information found in the annual reports and in the 10-Ks. Both groups cited classroom assignments as a significant use and stated that faculty often required a comparison of the $10-\mathrm{K}$ and the annual report. Other uses cited were for information on litigation, subsidiaries, and insider holdings and for assisting the university in soliciting contributions. An overwhelming number of libraries, citing the differences in information in each, indicated that they would not use the $10-\mathrm{Ks}$ in place of hardcopy annual reports.

Only 69 libraries collect foreign corporate annual reports (FAR); of these, 23 are from the subset. FARs are selected most often from the Fortune International 500, or from "whatever the library can get." (The latter is probably more an indication of the difficulty of collecting than a lack of a clear policy.) Other criteria given for selecting were by specific country and by specific industry. A small number of libraries select by "major foreign companies," on the basis of faculty requests, and from multinational companies or take 
Use

Career Information

Financial Information

Company History

Market Research

Corporates Officers

Public Relations

Personnel Policies

\section{Total \\ Respondents}
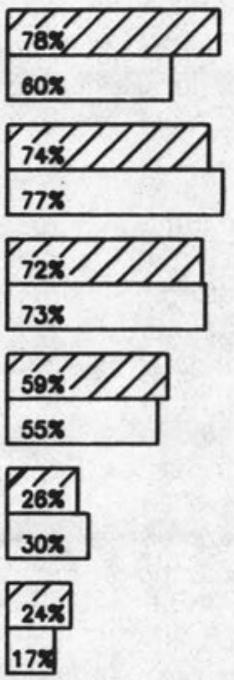

$P_{17 \pi}^{16 \%}$
Subset
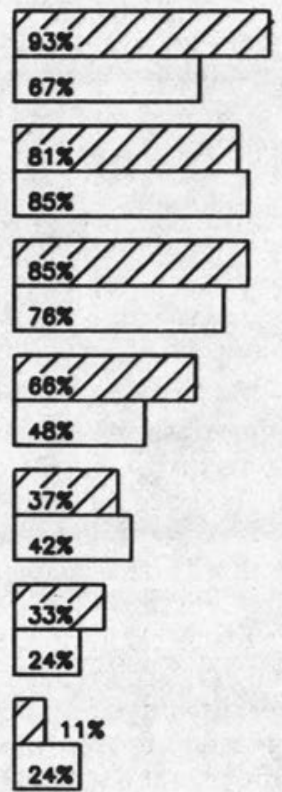

Hord Copy

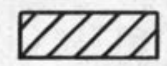

$10-K$

\section{FIGURE 2}

Comparison of the Major Uses of $10-\mathrm{K}$ and Hard-copy Annual Reports, as Reported by the Total Respondents and by the Subset

(Percentage of Libraries Reporting Use as One of Their Top Four Choices)

those they received as gifts or with their Q-Data subscriptions. As for the number of FARs received, 21 libraries obtain 1-25 per year; 20, 26-100; and 15, 101-500. Of the subset, 3 libraries receive 500 or more FARs per year; 43 of the libraries receiving Fars subscribe to a microform service, 14 of these being in the subset.

In section III, respondents were asked to comment on their circulation and cataloging policies. Libraries were evenly divided between those that circulate their hardcopy reports and those that do not. Most libraries do not circulate their microform reports, although one library circulates both the microforms and a reader. Those that circulate only under special conditions listed them as follows: to faculty or university officials, for a limited time for photocopying, only second copies of reports, overnight, for two hours for classroom use, or only the older, bound reports. The majority of respondents (274) do not catalog their annual reports. Several libraries, however, catalog reports of special groups of companies, such as those from the local/state area or older reports. Several libraries commented on the problems related to the theft of annual and $10-\mathrm{K}$ reports.

One of the more intriguing facts gleaned from the survey was the number of libraries that have online service capability but use it rarely or not at all to retrieve annual report information. Those libraries that commented said that they do not use 
it because of the lack of demand, associated with the high cost.

An attempt was made to determine if the size of the M.B.A. population in a particular program had any significance for particular acquisition strategies. The results of this tabulation are found in table 2. It is clear that in the libraries serving larger enrollments, financial ability and/or desire to take each of these types made their acquisitions almost equivalent, with some libraries commenting that the more stringent reporting requirements predisposed them to acquire $10-\mathrm{Ks}$. In the group of libraries serving the smallest number of M.B.A.'s, the acquisition of hard copy was predominant, the acquisition of $10-\mathrm{Ks}$ considerably less. For the subset, the percentage of libraries taking each of the forms of the domestic corporate reports is so great that the number of M.B.A.'s is irrelevant. There is only one library in the subset that receives neither the microform annual reports nor the hard copy, but it does receive the $10-\mathrm{K}^{\prime} \mathrm{s}$. Most take all three.

Figure 3's parts a and b provide a comparison of the number of libraries holding one or the other form of the domestic report. Note that only 3 libraries take only the $10-\mathrm{Ks}$. Most significant is that of the 335 libraries answering the questionnaire, only 26 take no corporate reports. This is very small percentage of the total, indicating the importance placed on the information in these reports.

Regarding changes in their current collection policies, 87 libraries planned to make some changes, 21 of these being in the subset. The major proposed change was to collect FARs. Plans to begin acquiring these on microforms were reported by
26 libraries ( 6 from the subset), and 6 were planning to collect the hard copy. Among other proposed changes listed, 19 libraries ( 5 of these in the subset) planned to begin discarding hard-copy domestic corporate annual reports, and 14 planned to begin or to increase their $10-\mathrm{K}$ collection ( 4 from the subset). Ten libraries planned to collect CARs on microform. Other proposed changes mentioned by 1-3 libraries were to begin collecting or to obtain more CARs, particularly from local companies; to cease collecting foreign hard-copy reports and to substitute the microforms mentioned above; to catalog the older hard-copy reports; to change vendors; and to use online services more extensively. One library in the subset planned to store historical material off-site.

\section{IMPLICATIONS}

This survey has given us a clear picture of present practices in annual-report collection by academic business libraries. The conclusions given below are based on both the numerical data elicited from the questionnaire and the written remarks of the respondents. There is no major difference in the collecting policies of annual reports in the subset of separate business libraries and the total group except, perhaps in the magnitude of collecting of the major research libraries. One might reasonably conclude that such widespread practices give validation to them in the sense that these practices satisfy the needs of a large number of faculty and students. They also indicate to those librarians who have not yet established policies that these practices have proven useful to a large group of their colleagues.

What can we learn from the survey that

TABLE 2

NUMBER OF M.B.A. STUDENTS IN COLLEGES SERVED BY RESPONDING LIBRARIES; AND LISTING OF TYPES OF CORPORATE REPORTS ACQUIRED

\begin{tabular}{lcccrr}
\hline \hline $\begin{array}{l}\text { Number of } \\
\text { MBA students }\end{array}$ & $\begin{array}{c}\text { Total } \\
\text { Respondents }\end{array}$ & Hard-copy & $\begin{array}{c}\text { Microforms } \\
\text { Annuals }\end{array}$ & 10-K & Foreign \\
\hline $25-199$ & 131 & 96 & 71 & 66 & 14 \\
$200-399$ & 71 & 61 & 37 & 48 & 20 \\
$400-699$ & 47 & 32 & 29 & 33 & 9 \\
$700-999$ & 19 & 16 & 16 & 17 & 8 \\
1000 or more & 26 & 20 & 21 & 22 & 12 \\
No answer & 41 & 30 & 17 & 15 & 6 \\
Totals & 335 & 255 & 191 & 201 & 69 \\
\hline
\end{tabular}


Figure 3a: Total Respondents (335 libraries)
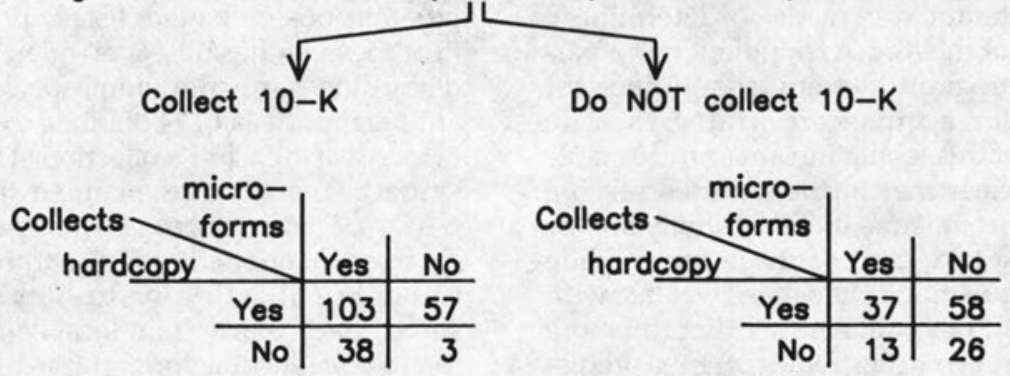

Figure 3b: Subset (37 libraries)
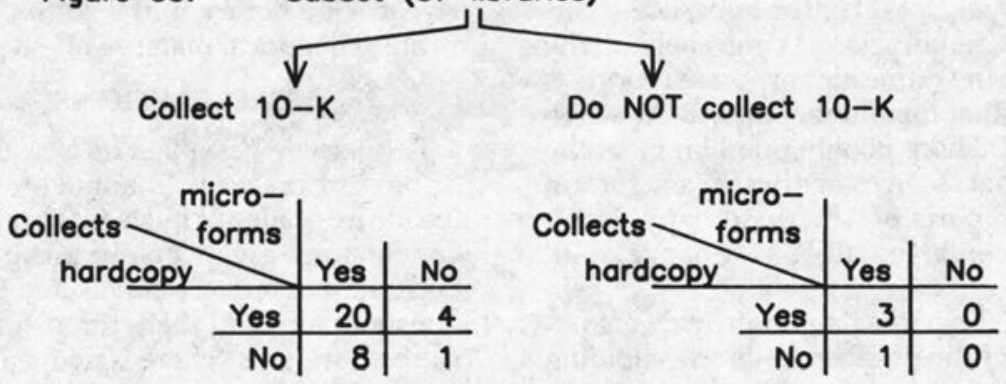

FIGURE 3

Forms of Annual Reports

by Number of Acquiring Libraries

will be of value in both collecting and weeding materials, as well as placing the material for optimum use and conservation of space? While there is always a danger in using descriptive material to make inferences regarding desirable policy, there are some trends that present themselves and some guidelines that can be extracted. One fact is obvious. Company annual reports are such an important source of primary information that every library with an undergraduate business program as well as those with an M.B.A. program should acquire them.

The least expensive means of acquiring corporate annual reports is to write to each company and ask for its annual report. Most will send it free of charge and domestic companies will put the library on their mailing list. One simple method of selecting the companies is to acquire those of the Fortune 500 industrial group; this is the choice of most libraries answering the survey. It would seem equally as important to have the reports of companies that are locally or regionally important available for student use, and/or reports of companies that represent an industry that is of local/regional importance. Companies that regularly recruit at the campus might also be considered for selection, particularly if there is no annual report collection in the placement office of the school. One staff member might be assigned to checking in and requesting the annual reports so that there is a consistent check on their receipt.

If funds are available, it is extremely de- 
sirable to order annual reports on microfiche. The library should check all the financial and selection options of each vendor and determine which ones are most suitable. ${ }^{6}$ One can order the Fortune 500 on fiche, or the entire list of companies on one of the exchanges, i.e., the New York Stock Exchange, the American Stock Exchange or Over-the-Counter stocks. One may also select companies individually. Again, the merit of selecting state/regional/or locally based companies should be considered. If the area is heavily involved in one industry, then one should consider ordering companies by industry. In any case a specific person should be assigned to review these selections once each year, to make certain that the appropriate companies are added to or dropped from the list. For example, if it is a burden to maintain the changes on the Fortune 500 list, then a regular schedule should be set up to make the changes, say every four or five years. Guides to the companies collected are essential so that library clients will know which company reports they may expect to find.

The study shows that the heaviest use of the hard-copy reports is for career-related information and job interviewing, with company financial and historical information a close second and third. In addition, students clearly demand the hardcopy reports in preference to microforms. At least one to two years of the hard-copy reports should be retained whether or not microforms are taken, and preferably, if space allows, three to five years. In the study, 47 percent of libraries retained their hardcopy for one to five years. After five years, in all but major research libraries, the annual hard-copy reports may be discarded if microforms are available. If the library is unable to budget a subscription for annual reports in microform, there is no clear picture, given by the survey, of how they should handle the weeding of the annual report collection. Certainly the reports of local- or state-headquartered companies should be kept for longer periods than other reports. In the case of libraries that maintain the only copy of such reports in a wide geographic area, there is an obligation to the community to maintain these reports indefinitely. In populous states, it would seem desirable for some cooperative effort to be made to make certain that corporate reports are maintained indefinitely by at least one library.

By maintaining some hard-copy reports for a period of several years, the library will also be able to satisfy the minority of clients who would like to see the company product displays, graphics, photography, quality of paper, etc. Another approach is for the library to acquire a limited number of the corporate annual report winners listed in Institutional Investor's "Best Annual Reports, ${ }^{\prime 7}$ or those listed in Financial World's "Annual Report Award Winners." Financial World makes awards to those companies that represent "significant overall accomplishment in the conception and execution of an annual report in the past year. Reflecting graphic and editorial considerations alike, the award recognizes more than aesthetic achievement, paying particular heed to the virtues of thoroughness, candor, and clarity of presentation. ${ }^{\prime 8}{ }^{8}$ These reports will allow students to see the best examples of design, graphics, typography, photography, and public relations copy. Each year a list of the acquired reports should be compiled and made available to library clientele.

It appears from the findings that the preferred location for hard-copy reports is in the reference department or in special alcoves. Filing cabinets in the reference department would serve to keep the current reports readily available for student use and also place them where assistance can be given and suggestions made for use. Some thought might be given to placing the latest one to two years in either the reserve or circulation area, for security reasons. Older annual reports might then be placed in less accessible locations. State and local reports, however, might be kept longer in their original location.

In collecting the $10-\mathrm{K}$ reports, funds are an important issue. While there is a clear perception on the part of librarians that the 10-Ks serve an important and distinct informational function in the library, they are not essential for every library. Many libraries can serve their student body without the $10-\mathrm{Ks}$ if they maintain some other type of corporate annual report. A limited 
number of $10-\mathrm{Ks}$ may be purchased, probably of local or state companies, in order to allow students the opportunity to compare the annual reports with the $10-\mathrm{Ks}$ and to be aware of the different contents of these reports. While the $10-\mathrm{Ks}$ do not satisfy the needs of students for career information as well as annual reports, they can be used to answer the historical and information needs of both faculty and students. (Some 10-Ks do include the annual report as part of the exhibits.) Significantly in our subset, more libraries subscribed to the 10-Ks than to the hard-copy annual reports.

While there is no one solution suitable for all libraries and all academic environments, the ideal mix for all but the large research libraries, would be hard-copy annual reports maintained for at least three years to accommodate those seeking career and job information. The paper copies, except for those related to local or regional companies, would be discarded after this time. Microfiche corporate annual reports would provide a good backup as well as providing the historical information needed. The $10-\mathrm{Ks}$ would be purchased for the New York and American Stock Exchanges, with additions of lo$\mathrm{cal}$ and regional companies from the OTC group. If budget considerations preclude buying a complete set of $10-\mathrm{Ks}$ for one stock exchange, selections of local and regional companies of interest could be made. Occasional use of online services could augment the corporate annual report collection.

Those libraries that want a strong program in international management should consider acquiring foreign corporate reports. Because contacting individual foreign countries is labor intensive, a budget for foreign reports on microfiche is desirable. As with domestic reports, inquiries should be made of all vendors as to their services and costs to find the best fit for the library. If the library plans to make direct contact, the Fortune 500 leading foreign companies list may be used or a list drawn up by countries or by industries that are of particular interest to the school. It should be assumed that receipts will not be as complete as one would like, and consider- able effort may be needed to see that reports are received. For example, faculty whose work requires extensive contact with foreign companies may be asked to assist in acquiring the reports.

Most libraries do not circulate microform annual reports or 10-Ks. The libraries in this survey were evenly divided as to whether they should circulate hard-copy annual reports. It would appear reasonable to circulate older hard-copy reports that are duplicated either in hard copy or microform and keep more current reports in a noncirculating collection. If the library is the primary state repository for state and regional reports, these should probably not circulate. Annual reports are normally shelved or placed in filing cabinets by company name rather than receiving any cataloging. Access can be through a simple check-in card file or merely by location indicated on a library guide sheet and noted in library location charts. Special reports, or older reports to be retained indefinitely, should be bound for preservation purposes.

The industry supplying various types of annual reports is in a considerable state of flux. New services, new options, new informational combinations are being offered frequently. In 1984, for example, one supplier ceased to provide foreign corporate reports and three other companies entered the field. One vendor is currently offering microfiche annual reports in conjunction with other materials useful for those seeking career information. Another vendor has introduced bonus points for adding to or renewing one's subscription; points which can be redeemed for library equipment. A development still in the formative stage is the introduction of the Security and Exchange Commission's Electronic Data Gathering Analysis and Retrieval System, known as EDGAR. ${ }^{9}$ Under the EDGAR system, companies will send their $10-\mathrm{K}$ and related data to the SEC electronically and it will be retrieved in the same manner, presumably by anyone with a personal computer. During the pilot project, which is expected to be completed by 1986,150 to 160 companies will provide information electronically as well as continuing to supply it in paper format. 
One needs to monitor this development to see what impact EDGAR will have on the information available in the $10-\mathrm{Ks}$ and/or the accessibility of that information to the public. It would behoove librarians to keep up with new trends, new vendors and new products offered in this area in order to get the greatest cost benefits for their library and to be certain that the information needs of their clients continue to be met.

\section{REFERENCES}

1. Madhava Balachandran, A Subject Approach to Business Reference Sources, Occasional Papers, no.128. (Champaign: Univ. of Illinois Graduate School of Library Science, June 1977), p.1-5. Although the information is slightly outdated, it still provides an excellent overview of the kinds of reports that companies provide to their stockholders, the stock exchanges, and the SEC.

2. Disclosure, Inc., A Guide to SEC Corporate Filings (Bethesda, Md.: Disclosure, May 1985). Provides an excellent summary of the various forms required by the SEC and their contents.

3. Eugene Miller, Barron's Guide to Graduate Business Schools 1984. 4th ed. (Woodbury, N.J.: Barron's Educational Series Inc., 1984).

4. Tracey Miller and Karen Sternheim, eds., College and University Business Library Statistics: 1979/80 and 1980/81, 5th ed. (Los Angeles: UCLA Graduate School of Management, May 1984), p.i.

5. Eugene Miller, Barron's Guide, p.40.

6. Judith Bernstein, "Corporate Annual Reports-The Commercial Vendors," College \& Research Library News 47: 178-80 (Mar. 1986).

7. "The Best Annual Reports," Institutional Investor 18:163-70 (Sept. 1984).

8. "The Art of Corporate Communication," Financial World 153:38-58 (Oct. 31-Nov. 13, 1984).

9. "SEC's Plan to Put a Mountain of Paper into a Computer," Business Week (Apr. 2, 1984), p.72-74; Susan Jayson, "Filing in the Future with EDGAR," Management Accounting 66:20-23 (June 1985); Shirley Hobbs Scheibla, "Egads, Edgar! What Has the SEC Wrought?" Barron's 65:24-26 (Aug. 26, 1985).

\section{APPENDIX A: INSTITUTIONS IN SUBSET}

Bentley College

Boston College

Clemson University

Columbia University

Cornell University

Dartmouth College

Harvard University

Howard University

Indiana University

Massachusetts Institute of Technology

Michigan State University

New York University

Northwestern University

Ohio State University

Purdue University

Stanford University

Tulane University

University of Alabama

University of California at Berkeley
University of California at Los Angeles

University of Chicago

University of Colorado

University of Connecticut

University of Illinois

University of Iowa

University of Michigan

University of New Mexico

University of North Carolina

University of Pennsylvania

University of Pittsburgh

University of Texas at Austin

University of Virginia

University of Washington

University of Wisconsin-Madison

Vanderbilt University

Wake Forest University

Washington University 


\section{INTERNATIONAL • MULTIDISCIPLINARY • INCLUDES COAUTHORS!}

\section{Put more than 850,000 author addresses at your fingertips...}

Now there's a valuable new source for the addresses of authors publishing in the sciences, social sciences, and the arts \& humanities: the Current Contents ${ }^{\circledR}$ Address Directory.

The Current Contents Address Directory can provide you with all the author addresses your patrons need in a wide variety of subject areas. Depending upon the disciplines your library serves, choose one or both editions of the Current Contents Address Directory: Science \& Technology, and Social Sciences/ Arts \& Humanities.

The Current Contents Address Directory has three indexes for fast, easy searching. The author index lists names and addresses of authors and coauthors, plus brief descriptions of their publications. The organization index provides access to author addresses by institutional affiliation, and the geographical index provides access by institutional location.

Order your copies of the Current Contents Address Directory now, and take advantage of these special prices: the Current Contents Address Directory-Science \& Technology is $\$ 345$; the Current Contents Address Directory-Social Sciences/Arts \& Humanities is $\$ 195$. Order both directories for just $\$ 490-$ a savings of $\$ 50$ off the combined price!
Please send me the following editions of the
Current Contents ${ }^{\circledast}$ Address Directory -1984
edition, covering authors who published during
1984 :
$\square$ Science \& Technology .............\$345
$\square$ Social Sciences/Arts \& Humanities .\$195
$\square$ Science \& Technology and Social
Sciences/Arts \& Humanities ........\$540 $\$ 490$

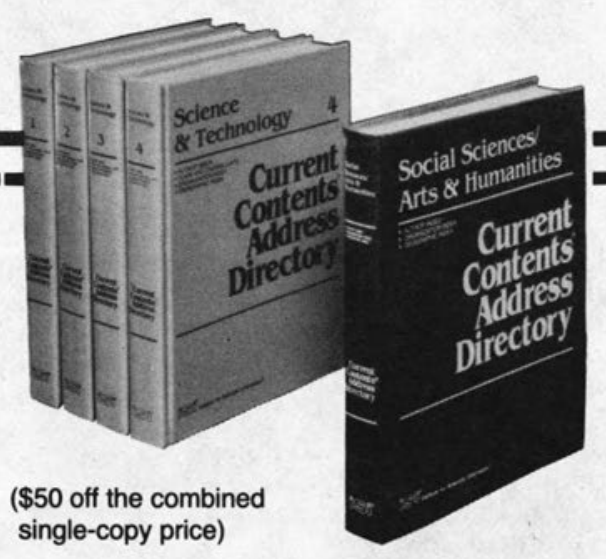

\section{NAMETITLE}

ORGANIZATIONVEEPT.

ADDRESS

CIT

STATESPROVINCE

COUNTRY

ป⿻ $\overbrace{}^{\circ}$ Institute for Scientific Information Fulfillment Services Department

3501 Market Street, Philadelphia, PA 19104 U.S.A. Telephone: (215) 386-0100, Cable: SCINFO, Telex: 84-5305 European Office

132 High Street, Uxbridge, Middlesex UB8 1DP, United Kingdom Telephone: 44-895-70016, Telex: 933693 UKISI

O19es isi $\quad 101-4243$ 